\title{
CR Research Suare \\ MEOX1 is a risk factor for unfavorable prognosis in human endometrioid endometrial adenocarcinoma
}

\section{Yunduo Liu}

Tumor Hospital of Harbin Medical University

Dan Kong

Tumor Hospital of Harbin Medical University

Tianbo Liu ( $\sim$ skyliu_1030@163.com )

Tumor Hospital of Harbin Medical University

\section{Xiuwei Chen}

Tumor Hospital of Harbin Medical University

\section{Research}

Keywords: Endometrioid endometrial adenocarcinoma, Immunohistochemistry, MEOX1, Prognosis

Posted Date: February 17th, 2020

DOI: https://doi.org/10.21203/rs.2.23728/v1

License: (c) (i) This work is licensed under a Creative Commons Attribution 4.0 International License. Read Full License 


\section{Abstract}

Background: Mesenchyme homeobox 1(MEOX1) is a homeobox transcription factor. Although MEOX1 has an impact on cancer, no studies investigated its expression in human endometrioid endometrial adenocarcinoma (EEA). This study aim to check the expression level of MEOX1 and detect its role in unfavorable prognosis.

Methods: We used Western blot analysis by fresh frozen tissues and Immunohistochemical (IHC) method to detect the protein levels of MEOX1.

Results: MEOX1 expression at the protein levels in EEA was gradually higher than that in normal group and benign hyperplastic endometrium group (both $P<0.001$ ). The high expression of MEOX1 was correlated with depth of myometrial invasion, lymfpho-vascular space involvement, FIGO stage冈lymph node metastasis and histological grade by univariate survival analysis. MEOX1 high-expression status in EEA was an independent prognostic factor for recurrence-free survival (RFS) and overall survival (OS) by Multivariate survival analysis. Kaplan-Meier analysis demonstrated that MEOX1 expression was related to RFS and OS. Compared with the high expression MEOX1group,the low expression MEOX1 group had longer RFS and OS (both $\mathrm{P}<0.001$ ).

Conclusion: MEOX1 may be a new potential biomarker for prognosis and recurrence in human EEA.

\section{Background}

Endometrial carcinoma is the most common cancer in female reproductive organs,and endometrioid endometrial adenocarcinoma (EEA) is the most common type [1]. Since endometrial carcinoma belongs to one of the gynecological cancers, more than 61000 patients with endometrial cancers were diagnosed in 2017, while the estimated death number was 10920 [2]. Although EEA is common in developed countries and regions, the duease has a good prognosis [3]. EEA tumors present as low-stage, welldifferentiated, that are confined to the uterus and are curable with surgery [4]. Approximately $20 \%$ of patients have a recurrence. Therefore, investigating therapeutic targets and reliable biomarker that can predict prognosis of EEA is needful.

MEOX1 is essential for the somite formation as a pivotal homeobox transcription factor [5]. It is located on human chromosome 17q21.31. According to some research, MEOX1 might promote the growth of carcinomas. Some research have demonstrated that in ovarian cancers MEOX1 mediates PBX1. MEOX1 is a cofactor of PBX1 and a pivotal target gene [6]. Besides, MEOX1 affected the progression of triplenegative breast cancer $[7,8]$. In addition, siRNA knockdown inhibits breast cancer cell frequency and the growth of tumor through down-regulation of MEOX1 [9]. However, the clinicopathological significance of MEOX1 in EEA remain unclear. Thus, in current paper, we aimed to explore MEOX1 protein over-expression in specimens of EEA.We also demonstrated that MEOX1 was associated with recurrence of EEA patients.

\section{Materials And Methods}




\section{Patients and tissue specimens}

We collected 201 cases of EEA patients, 50 cases of benign endometrial lesions (including atypical hyperplasia and complex hyperplasia) and 55 cases of normal endometrium from the Harbin Medical University Cancer Hospital between April 1, 2010 to June 30, 2012. Samples of EEA were obtained from patients undergoing hysterectomy, pelvic lymphadenectomy, para-aortic lymphadenectomy and bilateral salpingo-oophorectomy, while the benign and normal group were obtained from patients undergoing hysterectomy. All the patients had never been received radiation therapy or chemotherapy before surgery. 20 fresh EEA tissues, 20 normal endometrium specimens and 20 benign endometrial lesions were obtained for Western blot analysis. This study was approved by Harbin Medical University Medical Ethics Committee.

\section{Patient Cohorts And Clinical Follow Up}

Patients' mean age was $53.59 \pm 9.61$ years (26-79). The stages of tumor were assessed based on the International Federation of Gynecology and Obstetrics (FIGO) 2009 staging system. All EEA patients were followed regularly until study closing date (June 30, 2019) or until death. Median follow-up time was 65 (4 to 84$)$ months.

\section{Western Bolt Analysis}

A total of 20 fresh EEA samples, 20 normal endometrium specimens and 20 benign endometrial lesions were homogenized in RIPA buffer. The lysate was centrifuged at $16,000 \mathrm{~g}$ at $4{ }^{\circ} \mathrm{C}$ for 20 minutes. The background-corrected absorbance (BCA) method (Beyotime, China) was used to estimate the concentration. Equal amounts of extracts were electrophoresed on a SDS-polyacrylamidel gel and then transferred onto POLYVINYLIDENE DIFLUORIDE membranes (Millipore,BILLERICA, MA,USA). The filters were blocked with $5 \%$ dry milk one hour, incubated with MEOX1 rabbit polyclonal antibody (dilution 1:1000;HPA045214, Sigma-Aldrich,USA) at $4{ }^{\circ} \mathrm{C}$ for 24 hours. THE BLOTS WERE THEN INCUBATED WITH horseradish peroxidase secondary antibody at $37^{\circ} \mathrm{C}$ for 60 minutes. Enhanced chemiluminescence substrate (Millipore,BILLERICA,MA,USA) was performed. $\beta$-actin (WL0001, Wanleibio, China) was used as an internal control.

\section{Immunohistochemistry And Staining Evaluation}

The formalin-fixed tissues were routinely embedded in paraffin ,cut into $4 \mu \mathrm{m}$ thick sections that were stained with $\mathrm{HE}$. After immersing in buffer, the slides were autoclaved at $121^{\circ} \mathrm{C}$ for 15 minutes. The sections were incubated with a rabbit polyclonal antibody MEOX1 (HPA045214,Sigma-Aldrich; dilution $1: 100$ ) at $4{ }^{\circ} \mathrm{C}$ for 24 hours. The slides were immersed in $0.05 \%$ diaminobenzidine tetrahydrochloride (DAB). 
The expression of MEOX1 was evaluated by semiquantitative method [8]. The number of positive cancer cell was scored between 0 to $3(0,0 \% ; 1, \leqq 25 \% ; 2,26 \%-50 \% ; 3, \geq 50 \%)$. The staining intensity was scored between 0 to $3(0=$ no reaction; $1=$ weak; $2=$ moderate; $3=$ strong $)$. The overall score $=$ intensity score + positive percentage score. Scores of 4-6 were considered as high expression.

\section{Statistical Analysis}

The test data were statistically analysed by SPSS 19. Kaplan-Meier analysis was applied to draw the survival curves. The $\chi^{2}$ test was performed to assess the relation between clinicopathological variables and MEOX1 high-expression. The log-rank test was applied to evaluated the univariate analysis. Multivariate and univariate logistic regression were applied to evaluate the effect of MEOX1 high expression on cancer recurrence. $P<0.05$ was statistically significant .

\section{Results}

\section{MEOX1 expression was elevated in EEA}

Western blot was applied to detect the levels of MEOX1 expression. MEOX1 was IDENTIFIED as A BAND OF 31 KDA (Fig. 1). MEOX1 is overexpressed in EEA tissues, which WAS FURTHER CONFIRMED BY IHC. THE POSITIVE STAINING CELLS WERE MAINLY LOCALIZED within the nucleus (Fig. 2). MEOX1 high expression was positive in 54.7\% (110/201) of EEA. The proportion of MEOX1 high expression was $36.0 \%$ $(18 / 50)$ in benign endometrial lesion group, while $25.5 \%$ (14/55) in normal endometrium group. The rate of MEOX1 high-expression was higher in EEA group, compared with normal endometrium group $(\mathrm{P}=$ 0.001) and benign endometrial lesion gropu $(P=0.018)$. But there was no significant difference between benign endometrial lesion group and normal endometrium group $(P=0.391)$ (Table 1).

Table 1

Expression status of MEOX1 in different endometrial tissues

\begin{tabular}{|c|c|c|c|c|}
\hline & \multirow[t]{2}{*}{ No. } & \multicolumn{2}{|c|}{ MEOX1 expression status } & \multirow[t]{2}{*}{$\mathbf{P}$} \\
\hline & & \multicolumn{2}{|c|}{ High \% } & \\
\hline $\begin{array}{l}\text { Normal endometrium } \\
\text { Benign endometrial lesion } \\
\text { EEA }\end{array}$ & $\begin{array}{l}55 \\
50 \\
201\end{array}$ & $\begin{array}{l}14 \\
18 \\
110\end{array}$ & $\begin{array}{l}25.5 \\
36 \\
54.7\end{array}$ & $\begin{array}{l}0.001^{a} \\
0.391^{b} \\
0.018^{c}\end{array}$ \\
\hline \multicolumn{5}{|c|}{${ }^{a}$ EEA versus normal endometrium } \\
\hline \multicolumn{5}{|c|}{${ }^{b}$ benign endometrial lesion versus normal endometrium } \\
\hline${ }^{\mathrm{C}}$ EEA versus benign endo & rial & & & \\
\hline
\end{tabular}




\section{MEOX1 high-expression is associated with progression and poor survival in EEA}

The relation between MEOX1 and clinicopathological parameters in the 201 cases of EEA samples were displayed in Table 2. MEOX1 high-expression was significantly correlated with recurrence $(P<0.001)$, lymph node metastasis $(P<0.001)$, FIGO stage $(P=0.002)$, a deep myometrial invasion $(P=0.037)$, vascular or lymphatic invasion $(P=0.010)$ and histological grade $(P=0.004)$.

Table 2. Association between MEOX1 elevated expression and clinicopathological factors. 


\begin{tabular}{|c|c|c|c|c|}
\hline \multirow[t]{2}{*}{ Variables } & \multirow[t]{2}{*}{ No. of cases } & \multicolumn{2}{|c|}{ MEOX1 expression status } & \multirow[b]{2}{*}{$\mathrm{P}$} \\
\hline & & Low (\%) & High (\%) & \\
\hline Age (years) & & & & 0.485 \\
\hline$<54$ & 96 & $41(42.7)$ & $55(57.3)$ & \\
\hline$\geq 54$ & 105 & $50(47.6)$ & $55(52.4)$ & \\
\hline FIGO Stage & & & & 0.002 \\
\hline I & 105 & $59(56.2)$ & $46(43.8)$ & \\
\hline II & 53 & $21(39.6)$ & $32(60.4)$ & \\
\hline III-IV & 43 & $11(25.6)$ & $32(74.4)$ & \\
\hline Histologic grade & & & & 0.004 \\
\hline G1 & 79 & $47(59.5)$ & $32(40.5)$ & \\
\hline $\mathrm{G} 2$ & 73 & $25(34.2)$ & $48(65.8)$ & \\
\hline G3 & 49 & $19(38.8)$ & $30(61.2)$ & \\
\hline Depth of Ml & & & & 0.037 \\
\hline$<50 \%$ & 103 & $54(52.4)$ & $49(47.6)$ & \\
\hline$\geq 50 \%$ & 98 & $37(37.8)$ & $61(62.2)$ & \\
\hline LVSI & & & & 0.010 \\
\hline No & 143 & $73(51.1)$ & $70(48.9)$ & \\
\hline Yes & 58 & $18(31.0)$ & $40(69.0)$ & \\
\hline Lymph node metastasis & & & & $<0.001$ \\
\hline No & 157 & $82(52.2)$ & $75(47.8)$ & \\
\hline Yes & 44 & $9(20.5)$ & $35(79.5)$ & \\
\hline Recurrence & & & & $<0.001$ \\
\hline No & 152 & $81(53.3)$ & $71(46.7)$ & \\
\hline Yes & 49 & $10(20.4)$ & $39(79.6)$ & \\
\hline BMI $\left(\mathrm{kg} / \mathrm{m}^{2}\right)$ & & & & 0.495 \\
\hline$<25$ & 114 & $54(47.4)$ & 60 (52.6) & \\
\hline$\geq 25$ & 87 & $37(42.5)$ & $50(57.5)$ & \\
\hline ER & & & & 0.801 \\
\hline Negative & 82 & $38(46.3)$ & $44(53.7)$ & \\
\hline
\end{tabular}




\begin{tabular}{|lllll|} 
Positive & 119 & $53(44.5)$ & $66(55.5)$ & \\
PR & & & & 0.912 \\
Negative & 87 & $39(48.8)$ & $48(55.2)$ & \\
Positive & 114 & $52(45.6)$ & $62(54.4)$ & \\
& & & \\
\hline
\end{tabular}

FIGO: International Federation of Gynecology and Obstetrics; G1: Well; G2: Moderate; G3: Poor; EC: Endometrioid cancer; MI: Myometrial invasion; LVSI: Lympho-vascular space involvement; BMI: Body mass index; ER: Estrogen receptor; PR: Progesterone receptor.

Log-rank test and Kaplan-Meier analysis were applied to evaluate the survival time.Patients with MEOX1 high-expression were likely to be have shorter RFS ( $P<0.001$, Fig. 3B) and shorter OS $(P<0.001$, Fig. 3A). Univariate survival analysis showed that MEOX1 high-expression predicted an unfavorable RFS and OS $(P<0.001$; Table 3$)$. Lymph node metastasis $(P<0.001)$, vascular or lymphatic invasion $(P<0.001)$, deep myometrial invasion $(P=0.005)$, FIGO stage $(P<0.001)$ and histological grade $(P=0.001)$ were correlated with unfavorable clinical outcomes (Table 3).

Table 3. Univariate survival analysis of 201 patients with EEA 


\begin{tabular}{|c|c|c|c|c|c|c|}
\hline \multirow[t]{2}{*}{ Variables } & \multicolumn{3}{|l|}{ os } & \multicolumn{3}{|c|}{ RFS } \\
\hline & Median & 5-year (\%) & $P$ & Median & 5-year (\%) & $\mathrm{P}$ \\
\hline Age (years) & & & 0.279 & & & 0.206 \\
\hline$<54$ & 65.0 & 84.5 & & 63.0 & 79.9 & \\
\hline$\geq 54$ & 67.0 & 83.9 & & 63.0 & 74.5 & \\
\hline FIGO Stage & & & $<0.001$ & & & $<0.001$ \\
\hline I & 70.0 & 92.7 & & 68.0 & 90.0 & \\
\hline II & 63.0 & 86.3 & & 61.0 & 84.1 & \\
\hline III-IV & 60.0 & 61.8 & & 26.0 & 29.9 & \\
\hline Histologic grade & & & 0.001 & & & 0.001 \\
\hline G1 & 68.0 & 97.4 & & 67.0 & 92.3 & \\
\hline G2 & 63.0 & 78.4 & & 61.0 & 73.9 & \\
\hline G3 & 63.0 & 70.2 & & 35.0 & 54.1 & \\
\hline Depth of MI & & & 0.005 & & & 0.004 \\
\hline$<50 \%$ & 67.0 & 87.3 & & 65.0 & 83.8 & \\
\hline$\geq 50 \%$ & 65.0 & 77.6 & & 62.0 & 70.3 & \\
\hline LVSI & & & $<0.001$ & & & $<0.001$ \\
\hline No & 67.0 & 86.7 & & 65.0 & 82.6 & \\
\hline Yes & 63.0 & 71.6 & & 43.5 & 55.8 & \\
\hline Lymph node metastasis & & & $<0.001$ & & & $<0.001$ \\
\hline No & 67.0 & 88.0 & & 67.0 & 85.9 & \\
\hline Yes & 56.0 & 69.4 & & 34.0 & 40.2 & \\
\hline $\mathrm{BMI}\left(\mathrm{kg} / \mathrm{m}^{2}\right)$ & & & 0.143 & & & 0.188 \\
\hline$<25$ & 67.0 & 83.9 & & 65.0 & 80.3 & \\
\hline$\geq 25$ & 65.0 & 80.7 & & 62.0 & 72.8 & \\
\hline ER & & & 0.392 & & & 0.252 \\
\hline Negative & 64.0 & 85.1 & & 63.0 & 80.2 & \\
\hline Positive & 67.0 & 80.7 & & 65.0 & 75.0 & \\
\hline PR & & & 0.295 & & & 0.468 \\
\hline Negative & 65.0 & 78.3 & & 63.0 & 74.6 & \\
\hline
\end{tabular}




\begin{tabular}{|lcccccc|} 
Positive & 66.0 & 85.8 & & 63.5 & 75.8 & \\
MEOX1 expression status & & & $<0.001$ & & & $<0.001$ \\
Low & 67.0 & 94.4 & & 67.0 & 93.2 & \\
High & 62.5 & 71.8 & & 40.0 & 58.5 & \\
\hline
\end{tabular}

FIGO: International Federation of Gynecology and Obstetrics; G1: Well; G2: Moderate; G3: Poor; EC: Endometrioid cancer; MI: Myometrial invasion; LVSI: Lympho-vascular space involvement; BMI: Body mass index; ER: Estrogen receptor; PR: Progesterone receptor; OS: Overall survival; RFS: Recurrence-free survival.

Multivariate survival analysis demonstrated that MEOX1 high-expression together with vascular or lymphatic invasion $(P=0.001)$, FIGO stage $(P<0.001)$ and deep myometrial invasion $(P=0.039)$ were independently factors for RFS (Table 4). Multivariate survival analysis also suggested that MEOX1 highexpression together with FIGO stage $(P<0.001)$ and vascular or lymphatic invasion $(P=0.013)$ were independently factors for OS (Table 4).

Table 4. Multivariate survival analysis of 201 patients with EEA 


\begin{tabular}{|c|c|c|c|c|c|c|}
\hline \multirow[t]{2}{*}{ Variables } & \multicolumn{3}{|l|}{ OS } & \multicolumn{3}{|l|}{ RFS } \\
\hline & $\mathrm{HR}$ & $95 \% \mathrm{Cl}$ & P & $\mathrm{HR}$ & $95 \% \mathrm{Cl}$ & $\mathrm{P}$ \\
\hline \multicolumn{7}{|l|}{ FIGO Stage } \\
\hline I & $\begin{array}{l}1.000 \\
\text { (reference) }\end{array}$ & & \multirow{4}{*}{$\begin{array}{l}0.002 \\
<0.001\end{array}$} & $\begin{array}{l}1.000 \\
\text { (reference) }\end{array}$ & & \multirow{4}{*}{$\begin{array}{l}0.008 \\
<0.001\end{array}$} \\
\hline II & 3.501 & $\begin{array}{l}1.610- \\
7.613\end{array}$ & & 2.841 & $\begin{array}{l}1.320- \\
6.116\end{array}$ & \\
\hline IIIIIV & 6452 & $3244-$ & & 11586 & & \\
\hline \multicolumn{5}{|l|}{ Depth of MI } & & \\
\hline$<50 \%$ & \multirow{2}{*}{\multicolumn{2}{|c|}{$\begin{array}{l}1.000 \\
\text { (reference) }\end{array}$}} & & & & \multirow{3}{*}{0.039} \\
\hline$\geq 50 \%$ & & & \multirow[t]{2}{*}{0.093} & $\begin{array}{l}1.000 \\
\text { (reference) }\end{array}$ & & \\
\hline LVSI & 1.633 & $\begin{array}{l}0.921- \\
2.895\end{array}$ & & 1.808 & $\begin{array}{l}1.030- \\
3.172\end{array}$ & \\
\hline \multicolumn{7}{|l|}{ No } \\
\hline Yes & $\begin{array}{l}1.000 \\
\text { (reference) }\end{array}$ & & \multirow[t]{2}{*}{0.013} & $\begin{array}{l}1.000 \\
\text { (reference) }\end{array}$ & & \multirow[t]{2}{*}{0.011} \\
\hline status & 2.022 & $\begin{array}{l}1.161- \\
3.521\end{array}$ & & 2.057 & $\begin{array}{l}1.184- \\
3.576\end{array}$ & \\
\hline Low & & & \multirow{2}{*}{0.007} & & & \multirow{3}{*}{0.001} \\
\hline \multirow[t]{2}{*}{ High } & $\begin{array}{l}1.000 \\
\text { (reference) }\end{array}$ & & & $\begin{array}{l}1.000 \\
\text { (reference) }\end{array}$ & & \\
\hline & 2.613 & $\begin{array}{l}1.297- \\
5.261\end{array}$ & & 3.377 & $\begin{array}{l}1.669- \\
6.831\end{array}$ & \\
\hline
\end{tabular}

FIGO: International Federation of Gynecology and Obstetrics; MI: Myometrial invasion; LVSI: Lymphovascular space involvement; OS: Overall survival; RFS: Recurrence-free survival; HR: Hazard ratio; Cl: Confidence interval.

\section{MEOX1 High-expression Independently Predicts Recurrence In EEA}

The recurrence in EEA was related to FIGO stage $(P<0.001)$ and positive lymph node metastasis $(P=$ 0.014) (Table 5). Multivariate logistic regression analysis showed that lymph node metastasis, FIGO stage and MEOX1 high-expression were independently related to EEA recurrence (Table 5).

Table 5. Multivariate regression analysis of the association between recurrence and MEOX1 elevated expression in EEA 


\begin{tabular}{|lcclll|}
\hline Variables & B & S.E. & P & OR & $95 \% \mathrm{Cl}$ \\
\hline FIGO Stage & & & & & \\
I II & & & & & \\
III-IV & 0.595 & 0.504 & 0.238 & 1.813 & $0.675-4.864$ \\
Lymph node metastasis & 2.369 & 0.505 & $<0.001$ & 10.683 & $3.971-28.737$ \\
$\quad$ & & & & & \\
No & & & & & \\
Yes & 1.105 & 0.451 & 0.014 & 3.020 & $1.248-7.312$ \\
MEOX1 expression status & & & & & \\
$\quad$ Low & & & & & \\
$\quad$ High & 1.089 & 0.455 & 0.017 & 2.972 & $1.219-7.244$ \\
\hline
\end{tabular}

FIGO: International Federation of Gynecology and Obstetrics; B and S.E.: the parameter estimator of association coefficient and its standard error; OR: odds ratio; $\mathrm{Cl}$ : confidence interval.

\section{Discussion}

Although the prognosis remains good for patients with who are diagnosed with early stage EEA, some patients still die of tumor recurrence [10 - 16]. It is necessary to find other effective MOLECULAR targets for prognosis analysis.

MEOX1 is radical for somite formation. As all know,mutations of MEOX1 may cause Klippel-Feil Syndrome [17]. Previous studies showed that MEOX1 may be involved in the development of some carcinoma. MEOX1 was over expressed in several cancers than normal tissues, such as prostate cancer, ovarian cancer, non-small-cell lung cancer and breast cancer $[7,8,18,19]$. Also, MEOX1 is related to signaling pathway. One study showed that HER2 signaling regulated MEOX1 in HER2 + breast cancer [9].Another report demonstrated that MEOX may control Bapx1 expression [20].

We firstly evaluated MEOX1 expression levels in EEA. In our study we detected the status of MEOX1. Our study demonstrated that MEOX1 was significantly elevated in cancer group at protein levels by western blot analysis and IHC staining. MEOX1 high expression was positive in $54.7 \%$ of EEA. The proportion of MEOX1 high expression was $36.0 \%$ in benign endometrial lesion group, while $25.5 \%$ in normal endometrium group. THE HIGH EXPRESSION RATE OF MEOX1 WAS SIGNIFICANTLY HIGHER IN EEA group, compared with normal endometrium group and benign endometrial lesion group.MEOX1 may play an oncogenic role in EEA .

Our study use clinical EEA tissues to demonstrate the association between the expression of MEOX1 and clinicopathological factors. MEOX1 high-expression was significantly related to recurrence,positive lymph 
node metastasis, high histological grade, FIGO stage, a deep myometrial invasion and positive vascular or lymphatic invasion. This conclusion is consistent with some other studies.

MEOX1 may reflect the malignancy of the cancer. We used Kaplan-Meier analysis to draw the survival time. Patients with high-expression were likely to be with shorter OS and RFS. Univariate survival analysis demonstrated that MEOX1 high-expression was related with an unfavorable RFS and OS. Multivariate survival analysis showed that MEOX1 high-expression together with FIGO stage and positive vascular/lymphatic invasion for both OS and RFS.

As is known to all,some poorly differentiated EEA patients may develop pelvic lymph node metastasis [21]. Our results showed that MEOX1 high-expression was related to positive lymph node metastasis.FIGO stage, MEOX1 high-expression and lymph node metastasis independently correlated with recurrence.Unfortunately, there was no sensitive marker that could predict lymph node metastasis. We will look for more other factors that could predict lymph node metastasis in the future.

In conclusion, MEOX1 is overexpressed in EEA patients. MEOX1 high-expression is closely related to unfavorable prognosis and recurrence. MEOX1 may be a new potential biomarker for prognosis and recurrence in human EEA.

\section{Abbreviations}

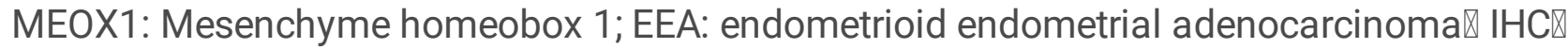

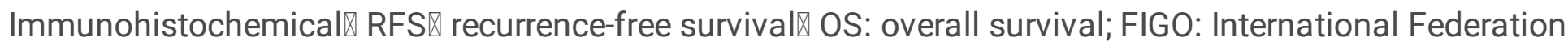
of Gynecology and Obstetrics.

\section{Declarations}

\section{Ethics approval and consent to participate}

This study was approved by the Ethical Committee of the Harbin Medical University Cancer Hospital.

\section{Consent for publication}

Consent was obtained to publish the paper.

\section{Availability of data and materials}

All data generated or analyzed during this study are included in this published article.

\section{Competing interests}

The authors declare that they have no competing interests.

\section{Funding}


This study was supported by grants the National Natural Science Foundation of China (No.81772274), the Key Projects of Haiyan Foundation of Harbin Medical University Cancer Hospital (JJZD2017-04), Nn10 program of Harbin Medical University Cancer Hospital, the Youth Elite Training Foundation of the Affiliated Tumor Hospital of Harbin Medical University (JY2016-03), the Key Projects of Haiyan Foundation of Harbin Medical University Cancer Hospital (JJZD2019-02) and Outstanding Youth Programme of Harbin Medical University Cancer Hospital (JCQN2019-06).

\section{Authors' contributions}

XWC conceived and designed the study. YDL and DK collected samples and processed data. TBL provided technical support. TBL analyzed data. YDL drafted the manuscript. XWC revised the manuscript. All authors read and approved the final manuscript.

\section{Acknowledgements}

Not applicable.

\section{References}

1. Camilla Mattiuzzi,Giuseppe Lippi.Cancerstatistics: a comparison between World Health Organization (WHO) and Global Burden of Disease (GBD).Eur J Public Health.2019 Nov 25. pii: ckz216. doi: 10.1093/eurpub/ckz216.

2.Siegel RL, Miller KD, Jemal A. Cancer Statistics, 2017.CA: a cancer journal for clinicians.2017;67:7-30.

3. Shannon N Westin,Russell R Broaddus.Personalized therapy in endometrial cancer: Challenges and opportunities.Cancer Biol Ther. Jan 1, 2012; 13(1): 1-13.

4. Odagiri T., Watari H., Hosaka M., et al. Multivariate survival analysis of the patients with recurrent endometrial cancer.Journal of Gynecologic Oncology.2011;22(1):3-8.

5. Mankoo BS, Skuntz S, Harrigan I, et al. The concerted action of Meox homeobox genes is required upstream of genetic pathways essential for the formation, patterning and differentiation of somites.Development.2003;130:4655-4664.

6.Thiaville MM, Stoeck A, Chen L, et al. Identification of PBX1 target genes in cancer cells by global mapping of PBX1 binding sites.PloS one.2012;7:e36054.

7.Lehmann BD, Bauer JA, Chen X, et al. Identification of human triple-negative breast cancer subtypes and preclinical models for selection of targeted therapies. The Journal of Clinical Investigation.2011;121:2750-2767.

8.Lichao Sun,Hebao Yuan,Joseph Burnett,et al.MEOX1 Promotes Tumor Progression and Predicts Poor Prognosis in Human Non-Small-Cell Lung Cancer.Int J Med Sci. 2019; 16(1): 68-74. 
9.Sun L, Burnett J, Gasparyan M, et al. Novel cancer stem cell targets during epithelial to mesenchymal transition in PTEN-deficient trastuzumab-resistant breast cancer.Oncotarget.2016;7:51408-51422.

10.Amant F, Moerman P, Neven P, et al. Endometrial cancer. Lancet. 2005;366:491-505.

11.Vance S, Yechieli R, Cogan C, et al. The prognostic significance of age in surgically staged patients with type II endometrial carcinoma. Gynecol Oncol. 2012;126:16-19.

12.Brown AK, Madom L, Moore R, et al. The prognostic significance of lower uterine segment involvement in surgically staged endometrial cancer patients with negative nodes. Gynecol Oncol. 2007;105:55-58.

13.Chen W, Zheng R, Baade PD, et al. Cancer statistics in China, 2015.CA: a cancer journal for clinicians.2016;66:115-132.

14.Yanokura M, Banno K, lida M, et al. MicroRNAS in endometrial cancer: Recent advances and potential clinical applications.EXCLI J.2015;14(5):190-98.

15.Winterhoff B, Konecny GE. Targeting fibroblast growth factor pathways in endometrial cancer.Curr Probl Cancer.2016;41(1):37-47.

16.Westin SN, Broaddus RR. Personalized therapy in endometrial cancer: challenges and opportunities. Cancer Biol Ther. 2012;13:1-13.

17.Mohamed Jawahir Y, Faqeih E, Alsiddiky A, et al. Mutations in MEOX1, Encoding Mesenchyme Homeobox 1, Cause Klippel-Feil Anomaly. American Journal of Human Genetics. 2013;92:157-161.

18.Zhu ZY,Wang XL,Li DP.Silencing of MEOX1 Gene Inhibits Proliferation and Promotes Apoptosis of LNCaP Cells in Prostate Cancer.Cancer BiotherRadiopharm. 2019 ;34(2):91-102.

19.Kun Dong, Xia Guo,Weiping Chen,et al. Mesenchyme homeobox 1 mediates transforming growth factor- $\beta$ (TGF- $\beta$ )-induced smooth muscle cell differentiation from mouse mesenchymal progenitors. $J$ Biol Chem. 2018; 293(22): 8712-8719.

20.Isabel Rodrigo, Paola Bovolenta,Baljinder S. Mankoo, et al. Meox Homeodomain Proteins Are Required for Bapx 1 Expression in the Sclerotome and Activate Its Transcription by Direct Binding to Its Promoter. Mol Cell Biol. 2004 Apr; 24(7): 2757-2766.

21.Yukiharu Todo,Sho Takeshita,Kazuhira Okamoto,et al. Implications of para-aortic lymph node metastasis in patients with endometrial cancer without pelvic lymph node metastasis. J Gynecol Oncol. 2017 ; 28(5): e59.

\section{Figures}



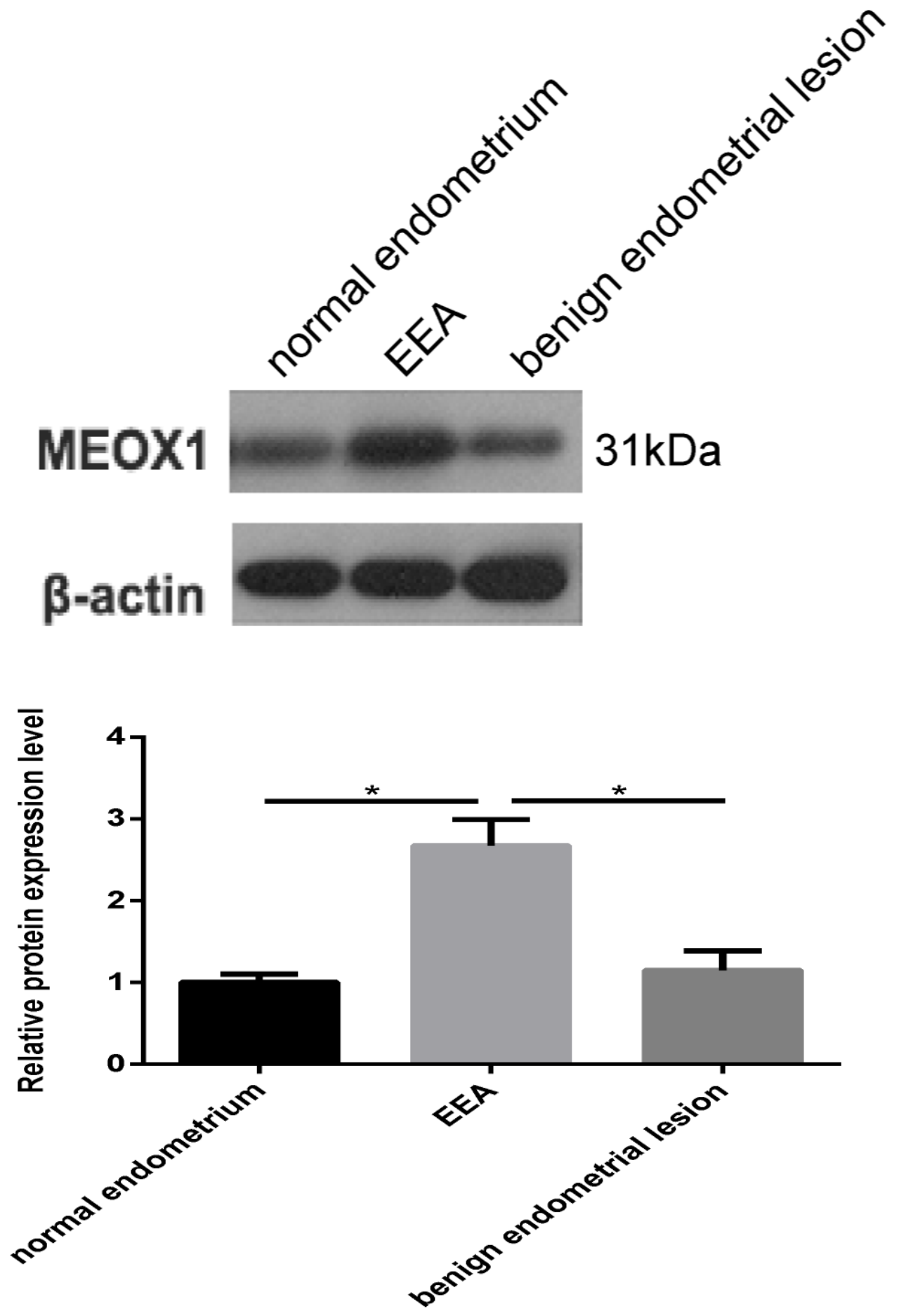

Figure 1

Western blot analysis of MEOX1 in 20 normal endometrium specimens $₫ 20$ fresh EEA tissues and 20 benign endometrial lesions. The expression of MEOX1 protein was significantly increased in EEA.The data are presented as $S D, * P<0.01$ 

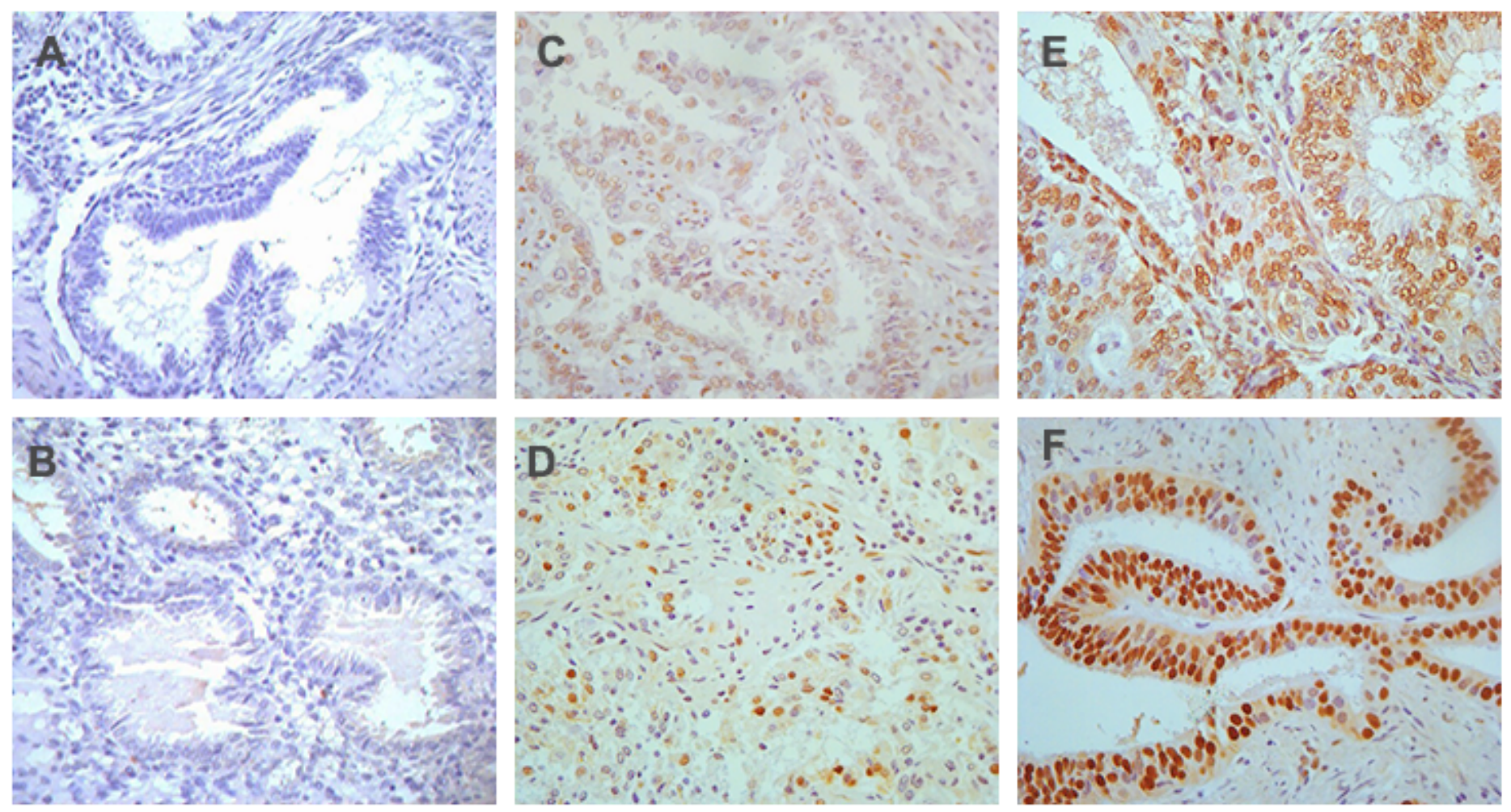

\section{Figure 2}

Representative examples of MEOX1 expression in endometrial tissue by immunohistochemistry. A and B: low expression of MEOX1 in normal endometrium .C and D : low expression of MEOX 1 in benign endometrial lesion.E and F:high expression of MEOX1 in EEA.

A

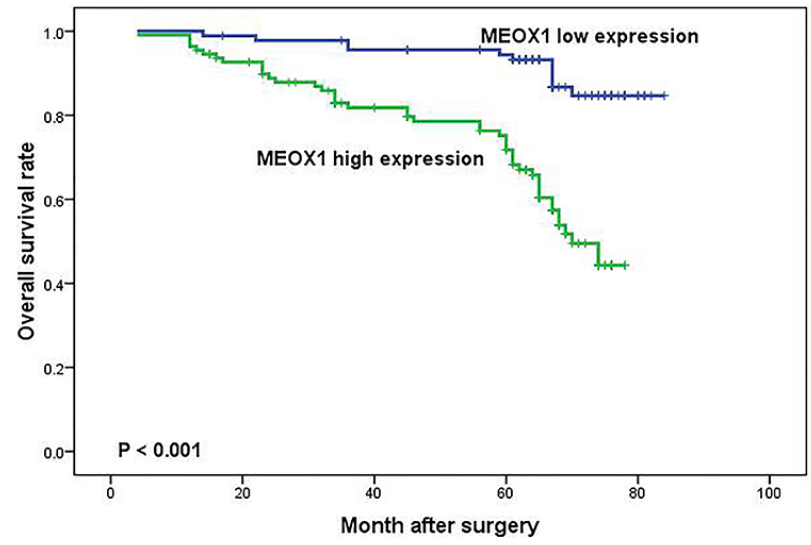

B

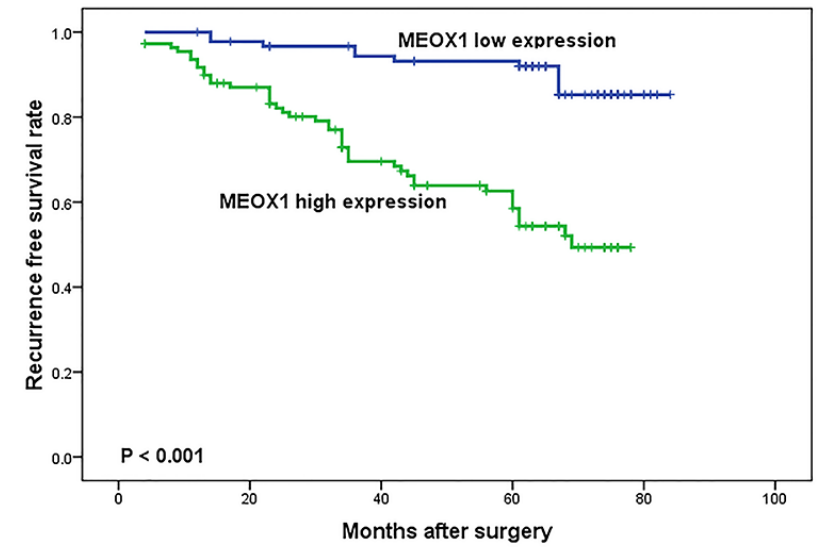

\section{Figure 3}

Kaplan-Meier curves for survival of prognosis in 201 patients with EEA according to the categories of low and high expression of MEOX1 (analyzed with log-rank test). A, Overall survival. B, Recurrence-free 
survival.

Page $17 / 17$ 